\title{
The problem of urban redevelopment of post-industrial King's Cross central area in London
}

\author{
Renata Jóźwik \\ Department of Landscape Design and Conservation, Faculty of Horticulture and Landscape Architecture, \\ University of Life Science in Lublin, e-mail: renata.jozwik@gmail.com
}

\begin{abstract}
The paper presents the strategy of redevelopment of the post-industrial King's Cross area in London - one of the biggest European investments in the last years (the surface of approx. 67 acres), which could be considered the perfect case study for similar works.

The author described in details the investment process, as well as the principles and effects of functional and spatial changes that have led to creation of the new system of open space, adaptation of selected post-industrial buildings for new functions (also the buildings proclaimed as a monument) and also fostering a new urban dimension to the wastelands. Detailed architectural issues are presented on the example of 3 squares: Granary Square, Pancras Square and King's Cross Square. Field research was realized from 2011 to 2016.
\end{abstract}

Keywords: urban design, redevelopment, King's Cross in London, renovation, urban area.

\section{Introduction and methodology}

The subject of the paper is total urban redevelopment of the King's Cross area. The said area has the surface of approx. 67 acres and is situated on the border of Camden and Islington districts. The urban redevelopment of the King's Cross area is one of the exemplary restoration process which had the great impact on London metropolis: the example of the sustainable development and of the interdisciplinary matters consisting of the development strategy, urban (the changes of functional and spatial connections) and social issues, and also architectural, cultural heritage protection, ecological, economical problems and the staging of the investment.

The transformation of the post-industrial areas in Western Europe, which lost their functional value in the 1970s, has been done according to individual rules. One of the important criteria (besides socio-economic) has been the ecological ability of the area to be restructured. For instance, the areas that had been previously occupied by the steel plant in Duisburg, were reclaimed and transformed into a landscape park, and the areas of the former Renault factory in Boulogne-Billancourt were designated for housing areas with commercial function of the island on Seine River. The subject of transformation and reclamation of the urban areas, especially post-industrial areas, was examined over and over again in many studies [1-4], also in the context of the similar areas in London (Canary Wharf) [5], and then in the paper referring directly to this region [6].

Post-industrial character of the transformed area results from its history: former railway stations and railway area with rails, magazines and warehouses, which have been dominating the area from the second half of $19^{\text {th }}$ century until their ultimate recapitalization in the $1980 \mathrm{~s}$. 
The time frame of the area development was divided into three stages - the first stage is "the first life" of the area: between its formation until its reclamation, then the period of transformation, and the last stage after this process. Thanks to this, it is possible to assess the results of the transformation.

Architectural problems were presented on the example of three squares: Granary Square, Pancras Square and King's Cross Square. The studies were based on the information provided by the investor, and also on observations in situ between 2011 and 2016. The conclusions of the studies were presented in the summary.

\section{The outline of the history of the area}

The strong point of the King's Cross area has always been transportation. The area started to be shaped in the vicinity of the crossing of the important roads - York Way and Pancras Road joining the northern English cities with London. At that time, the King's Cross area situated in the suburbs of London served as a recreation area for the residents of the polluted centre.

In 1820, Regent's Canal was built to support the system of transportation. Thanks to excellent communication system, industrial plants (e.g. Imperial Gas Light and Coke Company), warehouses, sorting plants and other similar objects started to spring up in the area. It was not optimal for the air quality. In $19^{\text {th }}$ century, the further development of the area was connected with the construction of railways for both freight and passenger traffic, and the infrastructure for both of these functions. Many buildings from that period were later were legally recognised as listed in conservation area. Development came to an end after war, in the 1970 s, when the popularity of the railway transportation went down dramatically in the whole Europe and maintaining heavy industry was not justified anymore. Decline of the area had severe social consequences, because the area populated by the workers has become urban wasteland, which fostered unemployment and social problems.

\section{Strategy, plan and implementation}

In the 1980s, the first attempts to activate this area were undertaken: tax advantages to new tenants were promised. The said area hosted the cheapest office spaces at that time. However, these efforts didn't bear fruits. Therefore, in 1990s, the special governmental institution was appointed to reclaim King's Cross area: King's Cross Partnership. Due to economic crisis of the 1990s, it was difficult for the new body to carry out their agenda, and yet the decision of 1996 to move international railway terminal from London-Waterloo station to St. Pancras station was sustained becoming the core issue of the current changes.

Planner's records at that time were favourable establishing multifunctional, high-density build-up area [7]. In 2007, Argent - the company that achieved success in the similar project in the spirit of sustainable development in Birmingham - was invited to cooperate with King's Cross Partnership. The development plan of King's Cross area was to take into consideration communal and housing needs, as well as historical issues (protection of historical sites and buildings), which were essential for the identity of the site. The adopted guidelines stipulated that forecasted communication flow will be 63 million of passengers per year in 2022 [8], thus urban arrangement of the area should be clear, capacious and safe. The other vital assumptions were as follows: formation of the new sites, full accessibility, lively 
and multifunctional area, proper use of the heritage, new workplaces, space for inspiration and optimal communication [9].

In 2004, an agreement was concluded with Camden and Islington communes, with the Mayor of London and English Heritage, as well as with the residents. Two years later, in 2006, after several sociological, economical and urban studies and consultations, the urban development plan was made by Allies \& Morrison Architects (in cooperation with Porphylios Association, Townshend Landscape Architects). The said plan became the basis for the issuance of the construction permit in December 2006 (triangle area - 2008). At that time, it turned out that too high density would negatively impact the quality of the area, thus its value. Consequently, the plot ratio was optimized. The area was divided into parts of a slightly different character. Construction permit contained quite novel solution that $20 \%$ of the surface could be arbitrarily customized during implementation of the plan. The only condition was to provide minimum $40 \%$ of so-called available apartments within the scope of planned 2000 new apartments. The development plan provided the given surface for the following purposes: offices $-455.500 \mathrm{~m}^{2}$, apartments $-194.000 \mathrm{~m}^{2}$, shops $-46.000 \mathrm{~m}^{2}$, hotels $47.000 \mathrm{~m}^{2}$, and the rest for open space and recreational purpose - entertainment surface [10]. During designing process, in February 2007, King's Cross Railway Lands Group questioned project for supposed breach of energetic and environmental standards and plans to demolish some buildings, but the court rejected this protest in May 2007 [11].

In 2007, railway terminal was opened at St. Pancras station offering connections with Paris (Channel Tunnel Rail Link). It entailed demolition of some buildings, relocation of historical gasometer, limitation of railway infrastructure, especially rails (some of the rails were built underground). Due to this, the additional area was reclaimed, which might have been reused (Fig. 1.).

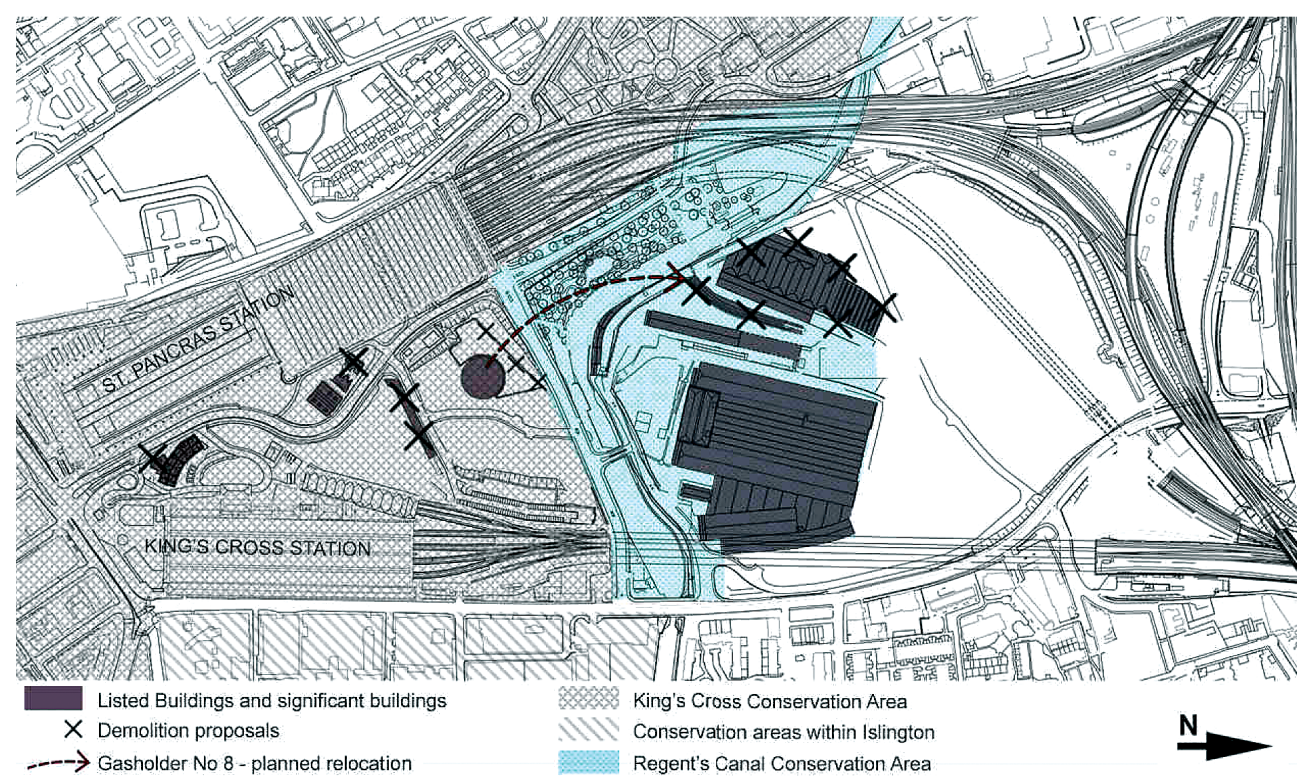

Fig. 1. Problems of conservation and decisions about demolition marked on the former development plan of the King's Cross area in London. Own elaboration, 2017 
Another important task was to create the map - active and accessible matrix with all the features, legal and formal requirement for individual parcels and objects in order to merge the area and to avoid expensive repayments and delays. In 2008, King's Cross Central Limited Partnership was created (shares: Argent - 50\%, London \& Continental Railways - 36,5\% and DHL $-13,5 \%$ ), who was proprietor of all of the area. Argent became the co-owner on the basis of the agreement for the obtaining of the construction permit and implementation of the connection with Eurostar line and after new estimation of the area. In January 2015, Australian Super - company dealing with pension funds (with the consent of EU) bought $25 \%$ of the shares in the investment, which confirms the success of the transformation.

\section{Architecture, composition, meaning - on the example of the three squares}

Kings's Cross Square, Pancras Square, Granary Square and Lewis Cubitt Square (completed after 2016) create legible interconnected system of the public space - each square has its own character, which was the aim of the design (Fig. 2).

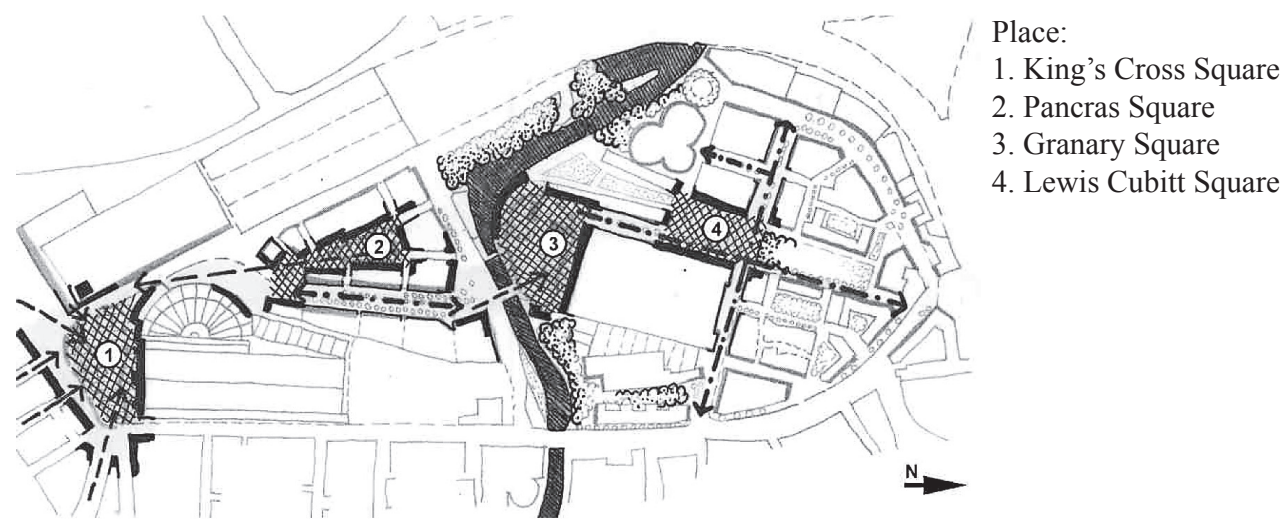

Fig. 2. The final development plan of the area indicating the new system of public space. Own elaboration, 2017

Granary Square in front of Central Saint Martins College was completed and opened within the scope of restoration in June 2012. Before transformation, in that place it was a basin adjacent to Regent's Canal, where the goods were unloaded from the barges. Existing building being the front and background of the square was built in 1852 according to Lewis Cubitt's project. It was a magazine / warehouse for the goods. In 2011, the object was restored and adjusted to the needs of Arts College by Stanton Williams Architects.

The layout was designed and implemented by Townshend Landscape Architects. The lightning was designed by Speirs+Major, the fountains - by The Fountain Workshop, and the other engineering issues were made by Peter Brett Associates.

Rectangular-shaped square can accommodate about 2000 people. It's exposed and open from the south, which ensures good light during the day. The main access is from the same side - with the passage over Regent's Canal, which gives main view on the whole square. Orientation towards the front of the building (background) and the square (floor) proves that the designers wanted to achieve scenographic effect. During works, the temporary viewpoint was 
made at this spot giving the possibility to observe the square under construction. The main attraction is the fountain built in the floor on 4 levels, which refer to the former basin. The architects have decided to use the elements of the former equipment of the site - e.g. rails built in the new surface. From the side of the canal, there are stairs that serve as little amphitheatre used among the others during open-air events.

The variability of the square, despite of its fixed elements is achieved through lighting, artistic and event-related arrangements. The square hosts various events. The front of the building is used for artistic video projections, e.g. the transmissions of Wimbledon Tournament, fashion festivals, food festivals, etc. In 2013, Swiss artist, Felice Varini, used Central Saint Martins building and the surroundings for his spatial installation.

There is not much greenery on the square, which refers to its former, industrial character. On the west side, there are 24 trees in 4 dense rows. Below, in their shadow, there are tables. Granary Square is often photographed by the students of Central Saint Martins, tourists and the audience of open-air events (Photo 1).

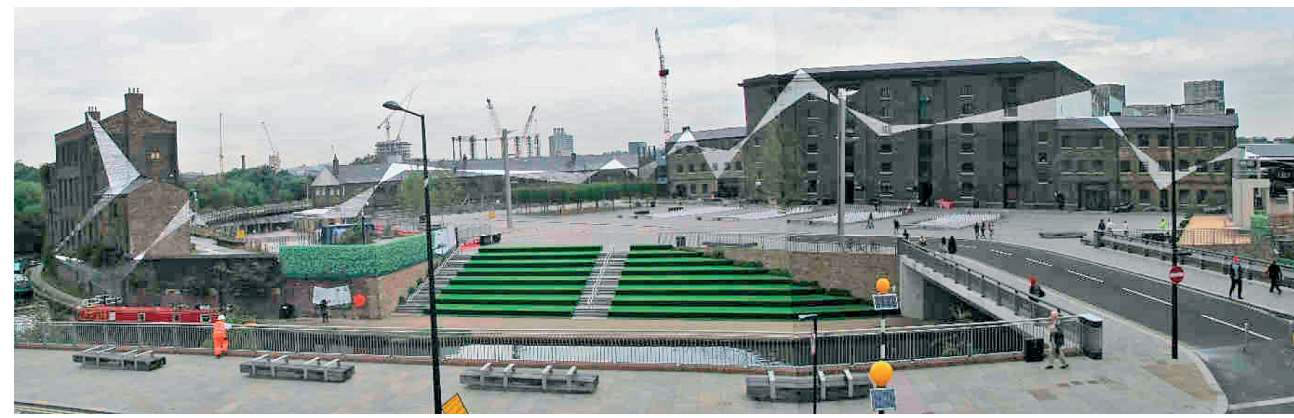

Photo 1. Granary Square - artistic installation of Felice Varini. Photo. R. Jóźwik, 2013

Pancras Square is the second square in the area of King's Cross. It has totally different character - it is an urban interior surrounded by the wall of block of houses between St. Pancras station and King's Cross station designed by Townshend Landscape Architects. The square is a kind of inner courtyard encircled by of 7 new, multifunctional, 10-storey buildings close to one another, which mainly hosts offices (among the others, the offices of Google). The shape of the square just like the whole quartier resembles triangle. Undeveloped grounds have the surface of about $4000 \mathrm{~m}^{2}$. On the one hand the square facilitate passage, but on the other hand, it encourages pedestrians to sit and rest. The exit zone - Battlebrigde Place - from the side of the exit from the King's Cross station, is the home for 12-meter oak which symbolically marks this area. Wooden seats were designed around the tree. There are the buildings at the background - One St Pancras Square (designed by David Chippefield) and lower, 5-storey Seven Pancras Square (designed by Studio Downie Architects) - Gridiron adjacent to the building with the status of monument of $2^{\text {nd }}$ degree - Stanley Building.

The leading theme of the square is water and greenery, which pass through the middle in a cascade creating more intimate and cosy places, at the same time not covering the surroundings. The main view from the square is the St. Pancras station tower anchored visually in the gap of buildings visible from the distance. In the foreground there are the buildings of Great Northern Hotel and German Gymnasium. Additionally, this effect is enhanced by exposition and reflection of the buildings at the surface of the water. Light and variability of arrangement of the ground floors make the scenery of the place dynamic (Photo 2). 


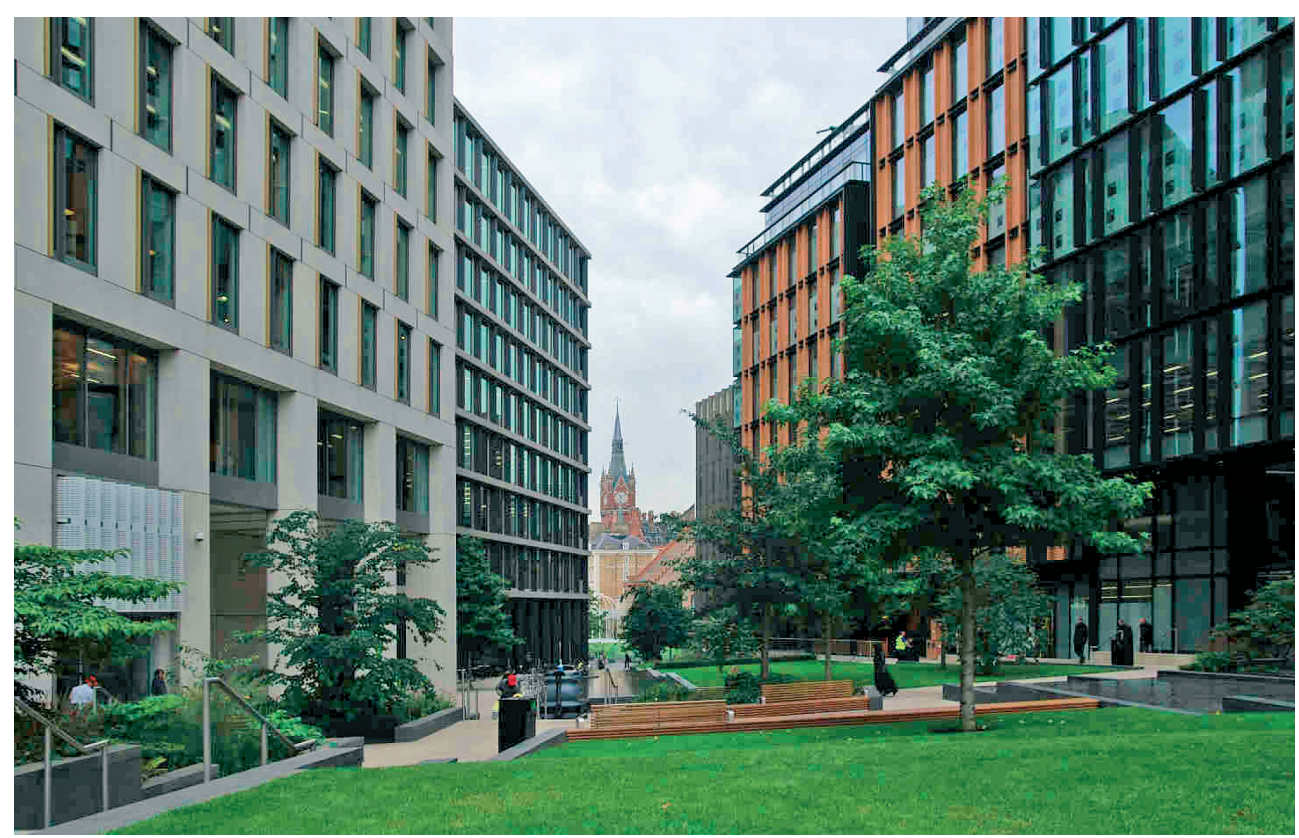

Photo 2. The Pancras Square - the view of St. Pancras railway station tower - Great Northern Hotel and German Gymnasium on the foreground. Photo: R. Jóźwik, 2015.

In 2008, the architectonic competition was organized for the design of public square in front of King's Cross station. First prize was won by the Stanton Williams architectural office. King's Cross Square was designed for Network Rail and was completed in 2013. Before, the whole surface was covered with roof; hence it was dark, tight and disorganized, hosting suburban commerce. The aim of the project was to organize the transport hub - to facilitate passengers' movement, give character to the entrance zone and crystalize the surroundings.

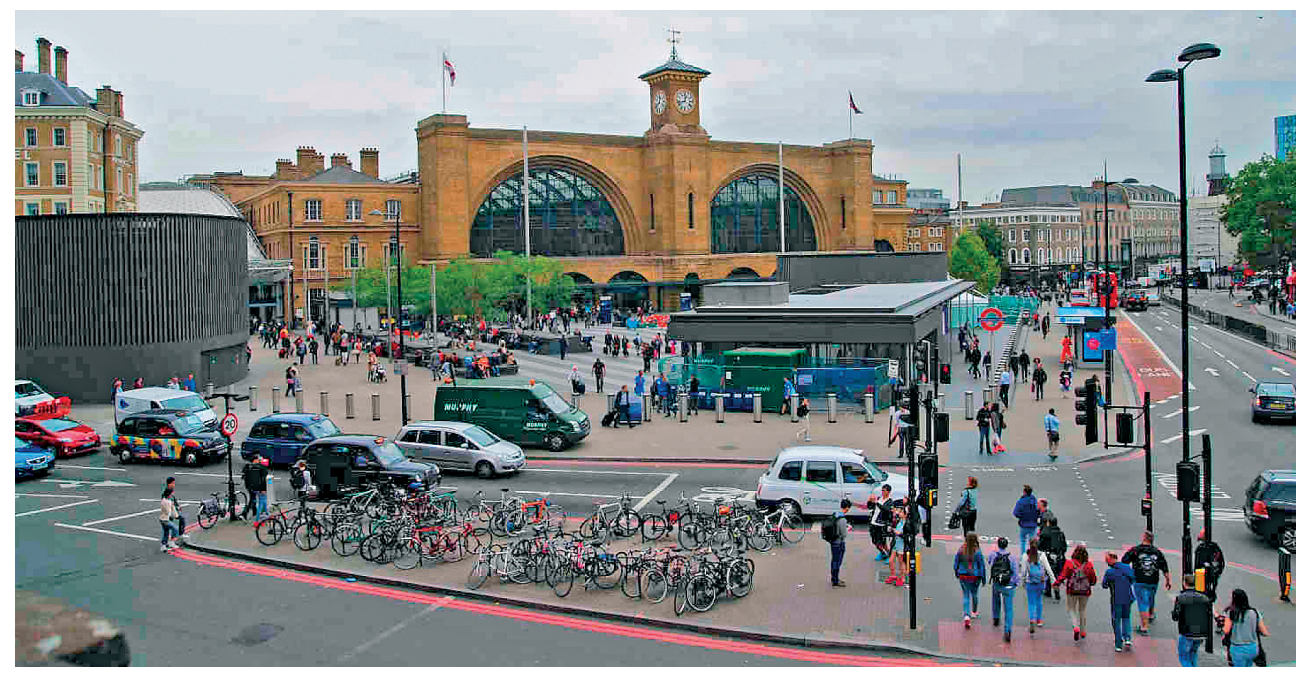

Photo 3. King's Cross Square - the view from the terrace of St. Pancras station. Photo: R. Jóźwik, 2015. 
The square has the surface of $7000 \mathrm{~m}^{2}$. The dominating, background element is the station building built in 1852 according to the design of Lewis Cubitt. The square is divided into two zones: passage zone and exit zone, which are market with zebra crossing. There is transparent roofing based on steel construction over the entrance zone adjacent to the building. There are different places where you can sit and relax - benches and seats carved in the small wall. There is also commercial mall with descent to King's Cross St. Pancras metro Station (Photo 3).

\section{Main conclusions}

1. The development impulse was to maintain the character of transport hub - with full communication service by public transport - and especially moving of Eurostar line terminal.

2. The motivation for change was among the other existing social structure in crisis, because of local unemployment, attractiveness of the location and cultural-historical potential.

3. The studies and consultations carried out and the monitoring of the investment process have contributed to the success of the development plan.

4. Thanks to flexibility in designing and innovation methods, it was possible to avoid additional costs and delays. Clarity and functionality of public space - interconnectedness and use of historical potential gave the character of the area.

5. Different urban character of the parts makes the area more attractive and facilitates orientation.

\section{References}

[1] Hollander J.B., Kirkwood N.G., Gold J.L. Principles of Brownfields regeneration. Island Press, 2010.

[2] Tallow A. Urban regeneration in the UK. Routledge 2013.

[3] Thompson Z. Urban constellation: spaces of cultural regeneration in post-industrial Britain (theory, technology and society). Routledge, London 2015.

[4] Roberts P., Sykes H., Granger R. Urban regeneration. SAGE 2017.

[5] Brenner D. King's Cross railway lands: A ,good argument” for change? Development Planning Unit UCL, London 2014.

[6] Bishop P., Williams L. Planning, politics and city making. A case study of King's Cross. RIBA Publishing, 2016.

[7] Strategic guidance for London Planning Authorities. Government Office for London (GOL), London 1996.

[8] Summers Ch. Cleaning up King's Cross, BBC news online. http://news.bbc.co.uk/2/hi/uk_news/ england/2550709.stm, access: 1.12.2017.

[9] Principles for a human city. Argent St George, London 2001.

[10] King's Cross Central, Allies \& Morrison. http://www.alliesandmorrison.com/project/kings-crosscentral, access: 1.12.2017.

[11] Judgement of the Court of Appeal: King's Cross Railway Lands Group v London Borough of Camden, Court of Appeal - Administrative Court, May 25, 2007, [2007] EWHC 1515. https:// high-court-justice.vlex.co.uk/vid/-52630692, access: 1.12.2017. 